\title{
TEORIA DA COMPLEXIDADE E RACIONALIDADE JURÍDICA CONTEMPORÂNEA: (RE)PENSANDO A COMPLEXIDADE DOS CONFLITOS
}

\author{
THEORY OF COMPLEXITY AND CONTEMPORARY LEGAL RATIONALITY: (RE) THINKING THE COMPLEXITY OF \\ CONFLICTS
}

\author{
TEORÍA DE LA COMPLEJIDAD Y RACIONALIDAD JURÍDICA CONTEMPORÁNEA: (RE) PENSANDO LA \\ COMPLEJIDAD DE LOS CONFLICTOS
}

\author{
MARTINAZZO, Celso José1 \\ SCHERER, Fernanda Serrer² \\ SILVA, Sidinei Pithan da ${ }^{3}$
}

\section{RESUMO}

O presente trabalho busca verificar as contribuições da Teoria da Complexidade na releitura do conflito e do modo como a racionalidade jurídica moderna tem legado ao Direito e à formação jurídica o papel de redutor das complexidades conflitivas. Parte da constatação de que a racionalidade jurídica moderna tem transformado divergências de interesses em permutas frias de argumentos em meio a procedimentos judiciais lineares e simplificadores. Em seguida, verifica as contribuições da Teoria da Complexidade para um novo olhar acerca dos conflitos, descortinando sua parcela caótica produtora de novas possibilidades de vida e convivência. Por fim, ancorado no pensamento complexo, tributa ao resgate da sensibilidade a chave para religar o ser humano a sua humanidade concebendo novos modos para o tratamento dos conflitos intersubjetivos a partir de uma relação dialógica que aproxime o valor da cultura das humanidades com as culturas tecnocientíficas em uma perspectiva reflexiva e humanizadora.

Palavras-chave: Racionalidade jurídica. Modernidade. Complexidade. Conflitos.

\section{ABSTRACT}

The present work seeks to verify the contributions of the Complexity Theory in the re-reading of the conflict and the way in which modern legal rationality has bequeathed to the Law and the juridical formation the role of reducer of the conflicting complexities. Departs from the finding that the modern legal rationality has transformed divergences of interests into cold exchanges of arguments amid linear and simplifying judicial procedures. Furthermore, verifies the contributions of the Theory of Complexity to a new look at the conflicts, revealing their chaotic plot producing new possibilities of life and coexistence. Finally, anchored in the complex thinking, attributes to the rescue of sensibility the key to reconnect the human being to his humanity, conceiving new ways for the treatment of the intersubjective conflicts from a dialogical relation that approaches the value of the culture of the humanities with the technoscientific cultures in a reflective and humanizing perspective.

Keywords: Legal Rationality. Modernity. Complexity. Conflicts.

\section{RESUMEN}

El presente trabajo busca verificar las contribuciones de la Teoría de la Complejidad en la relectura del conflito y del modo en que la racionalidad jurídica moderna ha legado al Derecho y a la formación jurídica el papel de reductor de las complejidades conflictivas. Parte de la constatación de que la racionalidad jurídica moderna ha transformado divergencias de intereses en intercambios fríos de argumentos en medio de procedimientos judiciales lineales y simplificadores. En seguida, verifica las contribuciones de la Teoría de la Complejidad para una nueva mirada acerca de los conflictos, descortinando su parcela caótica productora de nuevas posibilidades de vida y convivencia. Por último, anclado en el pensamiento complejo, atribuye al rescate de la sensibilidad la clave para reconectar el ser humano a su humanidad concebiendo nuevos modos para el tratamiento de los

\footnotetext{
1 Universidade Regional do Noroeste do Estado do Rio Grande do Sul - UNIJUí - ljuí - Rio Grande do Sul - Brasil

${ }^{2}$ Universidade Regional do Noroeste do Estado do Rio Grande do Sul - UNIJUÍ - ljuí - Rio Grande do Sul - Brasil

${ }^{3}$ Universidade Regional do Noroeste do Estado do Rio Grande do Sul - UNIJUÍ - ljuí - Rio Grande do Sul - Brasil
} 
conflictos intersubjetivos a partir de una relación dialógica que acerque el valor de la cultura de las humanidades con las culturas tecnocientíficas desde una perspectiva reflexiva y humanizadora.

Palabras clave: Racionalidad jurídica. Modernidad. Complejidad. Conflictos.

\section{CONSIDERAÇÕES INICIAIS}

Este artigo consiste em um ensaio que busca certa aproximação entre a Teoria da Complexidade, a educação e a racionalidade jurídica em geral, a fim de pensar a conflituosidade social como feixes de interações complexas. Metodologicamente, o espírito jurídico racionalizador da modernidade classifica e separa juridicamente as condutas humanas em lícitas e ilícitas, possíveis e impossíveis, válidas e inválidas, castrando a complexidade das ambivalências que brotam das subjetividades insatisfeitas das quais derivam os conflitos, judicializados ou não.

A racionalidade jurídica moderna, na esteira do modelo de racionalização cartesiano, muitas vezes toma o Direito como um redutor de complexidades. Formatada ao nível de estruturas normativas preconcebidas, a ciência do Direito corre o risco de traduzir, ao seu modo de linguagem, os seres humanos como sujeitos de direito, os conflitos como demandas judiciais e os acontecimentos da vida como fatos jurídicos. De posse desses elementos, funcionaliza as experiências vivas, e as converte em ingredientes para o desenvolvimento de uma ritualista processual com vistas à pretensão, sempre ambiciosa, de pacificação social ainda que, para tanto, tenha que valer-se da força que the foi legitimamente outorgada pelo Estado.

No imaginário jurídico moderno paira, portanto, uma pretensão de estabilidade, determinismo, segurança e certeza garantida pela manipulação de categorias jurídicas aprioristicamente formuladas. $\mathrm{Na}$ cadência das promessas da modernidade, o Direito passa a operar como um instrumento de concretização do ideário social de harmonia e equilíbrio, e aos conflitos é imputada a concepção de patologia social, mal a ser reprimido e eliminado a partir da prévia aplicação da lógica de disjunção dos contrários, ou seja, do positivo e do negativo, do verdadeiro e do falso, do amigo e do inimigo, do nacional e do estrangeiro, do eu e do outro.

Nesse sentido, a Teoria da Complexidade inaugura um novo olhar para o pensamento jurídico da contemporaneidade, marcado pelo reconhecimento dos muitos caminhos, produtos e produtores do humano, que se encontram na encruzilhada entre o corpo e a alma, a razão e a loucura, a indiferença e o desejo, a culpa e a redenção.

A partir dessa contextualização, o presente texto está estruturado em três momentos. O primeiro, em que se discutem as implicações da racionalidade instrumental moderna sobre o Direito e o modo como a Ciência Jurídica vem lidando com os conflitos intersubjetivos. O segundo, em que se analisam as contribuições do pensamento complexo para a crítica à leitura reducionista e simplificadora do mundo, do homem e do modo de produção e de difusão do conhecimento, com destaque para as ideias de Edgar Morin. E o terceiro, dedicado à aproximação entre a complexidade e o desvelamento de uma visão dos conflitos intersubjetivos como potenciais criativos, verdadeiros repositórios caóticos promotores de mudanças para os indivíduos e para a humanidade. Neste sentido, o percurso reflexivo 
no âmbito da teoria da complexidade nos permite compreender os desafios para os que lidam com a educação e a formação no campo do Direito.

De forma particular, Morin, nos desafia a criar um pensamento complexo na educação, o qual vá além do reducionismo do todo e da parte, superando a hiperespecialização e a compartimentalização. Morin sugere a necessidade de um pensamento que seja capaz de distinguir e unir ao invés de separar e fragmentar. Assim, nos desafia a compreender que a realidade é una e diversa, que comporta não apenas ordem, como também desordem e organização. Sua investida pode ser compreendida como uma forma de combate a toda cegueira produzida no âmbito do conhecimento, a qual se traduz em uma leitura empobrecida e mutilada da realidade e do mundo. Trata-se, neste sentido, de incentivar e desenvolver no âmbito da formação em Direito, o valor da cultura das humanidades (que possibilita uma cultura geral reflexiva sobre o mundo, o homem e a sociedade) em sua relação dialógica com as culturas tecnocientíficas (que possibilitam uma cultura profissional, instrumental e técnica sobre o Direito).

Neste sentido, o presente estudo visa a apontar para um horizonte de sentido que permita pensar um Direito implicado com o ser humano e todas as suas ambivalências, tradutor do coquetel da existência que se faz entre coerência e incoerência, ordem e desordem, racionalidade e irracionalidade, percepções neutralizadas pelo pensamento e pela linguagem empírico-racional que fundou o sentido comum teórico dos juristas da modernidade, caminho que se reveste de potencialidade e de desafio quando se assume sua relação com o percurso formativo das subjetividades que respondem pela área jurídica.

\section{MODERNIDADE E RACIONALIDADE JURÍDICA}

A modernidade fundou uma concepção de ciência e de epistemologia baseada em uma visão de mundo ordenada e regida por métodos pretensamente produtores de certezas. De modo geral, predomina no mundo moderno uma racionalidade que objetiva dar conta de explicar, a priori, mediante processos lineares e simplificadores, a natureza, os seres humanos e as suas interações sociais, econômicas e jurídicas. Esta perspectiva estruturante de mundo atravessou o universo educacional e jurídico em sua totalidade.

O pensamento cartesiano, para o qual se tributam as conquistas do desenvolvimento e do progresso do ocidente, desvincula o sujeito pensante da coisa pensada. Ao fragmentar e abstrair o fundamento dos pressupostos, a matéria do espírito, a realidade do mito, a razão da existência, o paradigma moderno apostou em um receituário empírico-racional de transparência, clareza e distinção iluminadora do conhecimento. Esta condição permitiu alicerçar o mundo moderno, ou mesmo o espírito moderno das luzes, que tanto influenciou no valor do Direito e da Educação para a constituição das subjetividades que viveriam sob e a partir das luzes da razão. 
No centro do palco moderno, triunfa o indivíduo autônomo, racional, emancipado dos grilhões mítico-religiosos e titular das promessas de um futuro melhor, garantido por uma racionalidade crescente, forjada em acordos produzidos por homens justos e razoáveis e caracteriza uma aposta em uma ciência que possa avançar na direção da verdade e uma ética assentada em um ideário universalista fundamentado em normas instituídas racionalmente. Essa aposta foi imensamente importante para romper com as formas de dominação pressupostas pelo antigo regime político no mundo europeu, mas que também guarda em si novas contradições e ambivalências que precisam ser discutidas nos âmbitos do Direito e da Educação.

Para Morin (2003a), o paradigma moderno orientou a grande aventura do conhecimento científico e das teorias filosóficas do ocidente desde o século 17 e permitiu, sem dúvida, a realização de grandes progressos e feitos para a humanidade; entretanto, fundou uma inteligência cega, incapaz de compreender a complexidade da realidade antropossocial, seja sob um olhar microdimensional que tem foco no indivíduo, seja sob uma perspectiva macrodimensional, de humanidade, de conjunto planetário.

Uma inteligência cega destrói os conjuntos, aniquila as totalidades, separa e contrapõe o uno ao múltiplo e joga para fora do homem-problema os problemas do homem. Morin (2003a) chama atenção para a necessidade de tomar consciência da patologia contemporânea do pensamento, afirmando que a hipersimplificação esconde a complexidade do real, que o dogmatismo e o doutrinarismo encapsulam a teoria sobre ela própria e que a racionalização encobre a parcela irracionalizável do real. Este caminho não nos coloca de forma alguma na direção contrária às luzes, tampouco, à própria razão, mas nos desafia a repensar a razão, ou mesmo o pensamento que fundou o Direito moderno e a Educação moderna.

O Direito, por não escapar aos pressupostos operacionais da modernidade, firmou suas bases na crença de que os juristas, a partir de um ensino jurídico cartesiano, desenvolvem habilidades e competências para a manipulação de fórmulas explicativas e resolutivas da totalidade conflitiva da condição humana. Com base em um mapa traçado por metadiscursos jurídicos, ao espelho das grandes narrativas fundadoras da modernidade, a Ciência Jurídica inaugura um sistema de Direito que pode realizar o sonho da tradução de uma realidade, dos fatos que constituem os direitos, em um silogismo lógico de encaixe perfeito com o conteúdo preestabelecido de modo unívoco nos grandes códigos e sistemas normativos.

A esse respeito vale lembrar a defesa que Kelsen (2006) faz sobre a necessidade de elaboração de uma ciência pura do Direito. Ao elaborar sua "Teoria Pura do Direito" buscou depurá-la de toda e qualquer expressão oriunda das demais ciências, da Filosofia, da Política, da Moral. Um Direito positivo autossustentável e que não poderia condicionar a validade de suas normas a um conjunto de preceitos axiológicos, pois em uma sociedade em que os valores são relativos é preciso que o Direito encontre dentro de si, em uma outra norma do próprio sistema, seus fundamentos legitimadores. Em outras palavras, uma teoria jurídica consciente da sua especificidade, pois fundada na legalidade específica de seu objeto. 
A essa pretensa harmonia e univocidade de olhar sobre o discurso de legitimação do Direito como ciência não escapam as concepções de cidadania, educação e de direitos humanos na modernidade, as quais, em boa parcela, convergiram de modo idealizado e fora de qualquer relação com a existência. Os juristas, sustentados no uso performático da linguagem, convergem em seus discursos, porém, um tanto fora da realidade. No plano formal jurídico, sujeitos são dotados de direitos pelo fato de ter a norma, aprioristicamente, assim os reconhecido. No entanto, o Direito vivo, em movimento, denota que quando um indivíduo encontra a sua cidadania insatisfeita, seja no plano do gozo dos direitos individuais ou sociais, como é o caso do acesso à educação, quase sempre traduz uma insatisfação na ordem dos direitos humanos.

Tais expressões, portanto, para muito além de pretensões autistas e cúmplices de discursos retóricos e poucas atitudes vitais, possuem uma história de sentidos carregada de imprecisões e de perplexidades "algumas vezes dependentes de zonas de vaguidão; outras manifestando confusas ambigüidades" (WARAT, 2001, p. 155). Conceitos portadores de um estado contínuo de tensão entre a razão e a sensibilidade, entre a cultura e as experiências históricas continuamente insatisfeitas.

Com a positivação dos direitos, inclusive dos direitos humanos, e de uma noção de cidadania restrita à participação na coisa pública - participo, logo existo -, o homem moderno, encapsulado como sujeito de direito, abriu mão de boa parte de suas subjetividades, entregando ao Estado, a quem acredita auxiliar na medida de sua participação democrática, a administração de seus conflitos, destituindo-se de sua autonomia na tomada das medidas coercitivas sobre as suas próprias insatisfações. Warat (2001, p. 161) postulando em nome da teoria crítica do Direito afirma que

[...] em nome dos direitos humanos e da cidadania, o Estado moderno nos foi levando a um crescente estado de desumanização (inclusive dos próprios Direitos Humanos). [...] entendendo por humanização a possibilidade de escapar das condições de alienação (em muitos casos determinadas pelo próprio Direito) e fugir para as condições de produção e realização existencial da autonomia.

Enfim, as verdades científicas, bem acolhidas no berço do discurso jurídico racional da modernidade, têm buscado calar a indagação, o erro, a incerteza e transformar conflitos inconciliáveis de interesses, produzidos pelas ambiguidades humanas, em permutas reguladas por argumentos racionais entre litigantes ${ }^{4}$, considerados pelo sistema como formalmente iguais. Assim, em um tribunal, o conflito se converte em um diálogo entre advogados, peritos e juiz; e o processo, em um procedimento ordenado com vistas à verdade, traduzindo-se em "uma das dimensões do efeito simbólico do ato jurídico como aplicação prática, livre e racional de uma norma universal e cientificamente fundamentada" (SPENGLER, 2011, p. 216). No âmbito educacional, muitas vezes, não há o entendimento acerca da complexidade do que está envolto no fenômeno científico e pretensamente racional e normativo do Direito moderno. E este silêncio em torno do problema do conhecimento se traveste em forma de entendê-lo como perspectiva funcional, ou seja, uma norma que

\footnotetext{
${ }^{4}$ No uso da linguagem jurídica, os conflitos, uma vez judicializados, passam a se denominar litígios; os conflitantes
} são denominados partes e o conflito renomeado como demanda. 
meramente precisa ser aplicada, sem carecer de uma interpretação complexa acerca do contexto dos envolvidos.

Como procedimento, cujo escopo é a busca da verdade, o processo judicial não permite comunicação direta entre os conflitantes, pois em nome da neutralidade na formação da consciência do julgador e da indiscutível parcialidade de todos os sujeitos envolvidos na reconstrução histórica dos fatos, as relações processuais são todas indiretas, bem como o próprio julgador deve estar despido de juízos pessoais valorativos, que poderiam contaminar de modo irremediável a decisão. Assim, "quando se vai ao juiz se perde a face" (RESTA, 2004, p. 114).

Todavia, vivemos o tempo em que a capacidade para formular soluções ou resolver demandas é infinitamente menor do que a capacidade de produzir riscos e problemas. Como acentua Rocha (2001, p. 134), do paradoxo entre o tempo e o Direito verifica-se um problema, ou seja, "temos uma racionalidade jurídica tradicional de repetição [...] e, ao mesmo tempo, temos necessidade de tomar decisões mais sociais, mais políticas, levando-se em consideração o novo tempo da sociedade, sociedade do futuro". Transposto para a educação, este problema amplia a necessidade de uma formação alargada e complexa, que inclui nos sujeitos educandos uma capacidade de pensar, a partir de um diálogo amplo e profundo, com o real e os diferentes contextos do mundo vivido, a partir da filosofia, das artes, das ciências (humanas e naturais).

No âmbito do Judiciário, em razão do paradoxo entre tempo e Direito, o mesmo precisa fazerse mais plural, voltado à produção e ao reconhecimento da diferença, e não tão somente à reprodução das fórmulas antecedentes, o que significa incorporar uma racionalidade complexa para pensar os fenômenos.

A abertura de uma nova janela para o pensamento jurídico, capaz de fazer frente aos conflitos, passa pela recuperação da humanidade no Direito, pelo resgate das subjetividades que foram relegadas em nome da segurança jurídica e de uma troca de lentes em relação às energias antagônicas presentes nos vínculos conflitivos, podendo vê-las como oportunidades criativas para encontrar o outro do conflito, invisível no paradigma individualista e simplificador da modernidade. À educação compete não somente a crítica do paradigma tradicional que funda o pensamento jurídico moderno, como também a instauração do novo, que permite outras formas de agência aos sujeitos.

Essa janela que se abre para o novo no pensamento jurídico pressupõe a tomada de consciência acerca das complexidades humanas nas quais os conflitos judicializados ou não estão embebidos, e a necessidade de religar o que a racionalidade moderna separou, formando uma rede de múltiplas dimensões - do homem com o cosmo, com a natureza, com o outro e consigo mesmo ocupada com a experimentação de formas de viver com mais qualidade de vida. Está em questão o reconhecimento e o valor da cultura das humanidades, que permite às subjetividades que interpretam os conflitos e a vida humana em geral, a partir do Direito, ganharem destaque e centralidade na formação superior em Direito.

O paradigma simplificador possibilitou avanços imensos em termos da hiperespecialização e da divisão social do trabalho, em todas as áreas do saber e da vida humana em geral, mas produziu 
novas cegueiras e unidimensionalizações, as quais passam a ser questionadas neste novo horizonte paradigmático que emerge ao longo do século 20. Em termos de pensamento jurídico, em sua busca por tornar-se puro e independente de toda a vida social e cultural humana, acabou por tornar-se uma referência para constituir a formação em Direito. O resultado desta redução de complexidades permitiu edificar certa noção de verdade, de conhecimento e de ideal formativo, o qual parece exigir do operador e do intelectual do Direito uma formação profissional que se centra hegemonicamente na Ciência do Direito (cultura tecnocientífica) em detrimento ou menosprezo à relação do Direito com todas as outras áreas do saber (cultura das humanidades).

Nesse sentido, são inúmeras as contribuições da Teoria da Complexidade arquitetada por Morin, para pensar a educação e a racionalidade moderna em geral. Interessa-nos, de forma particular, analisar como este enfoque nos ajuda a repensar o pensamento jurídico, bem como a própria noção de conflito que tem se presentificado nesta e na formação superior em Direito.

\section{CONTRIBUIÇÕES DA TEORIA DA COMPLEXIDADE PARA A REINVENÇÃO DO PENSAMENTO JURÍDICO}

Os pensamentos, as ações e os modos de produção do conhecimento estão relacionados diretamente com um paradigma, ou seja, com uma estrutura racional de ideias inscrita, culturalmente, em cada um dos homens e no produto de suas interações no âmbito da vida social. Nesse sentido, Morin defende que para compreender o problema da complexidade, é preciso, primeiro, saber o que é o paradigma da simplificação, e chama a atenção para o fato de que um paradigma é constituído por relações lógicas, por noções-chave e por princípios basilares que vão "comandar todos os propósitos que obedecem, inconscientemente, ao seu império" (MORIN, 2003a, p. 85).

Cumpre sinalizar que o paradigma da simplificação, conforme Morin interpreta, é tributário do pensamento de René Descartes constituído no século 17. Este nos ensinou a separar e disjuntar ao invés de diferenciar e unir. Imaginava-se, neste cenário que o conhecimento era o espelho da realidade ou mesmo o espelho do mundo. Três ideias poderosas alimentaram o paradigma da simplificação: a ideia de ordem, de separação e razão. Descartes, na esteira de Galileu Galilei, projetou a imagem do Universo como se fosse uma máquina, e idealizou a perspectiva que alimentou a ideia de conhecimento/explicação do racionalismo clássico, o qual pressupunha que a aparente complexidade dos fenômenos poderia ser explicada por princípios simples, em outros termos que "[...] a espantosa diversidade dos seres e das coisas podia explicar-se a partir de alguns elementos simples" (MORIN, 2001, p. 27).

Esta ideia de um universo ordenado deu origem a uma concepção de racionalidade, pressupondo que o real poderia ser desvendado pelo pensamento a partir de uma noção de razão: "um método de conhecimento baseado no cálculo e na lógica (na origem, ratio significa cálculo), empregado para resolver problemas postos ao espírito, em função dos dados que caracterizam uma situação ou um fenômeno" (MORIN, 2001, p. 157). Também possibilitou a emergência do que é conhecido como 
racionalismo: a) uma visão de mundo que afirma a concordância perfeita entre o racional (coerência) e a realidade do universo; uma ética que se sustenta na ideia de que as condutas e finalidades humanas, bem como a vida social em geral, precisam se amparar na racionalidade (ibidem).

Os princípios da simplificação aplicavam-se a esses fenômenos, segundo Morin, por separação e redução. A primeira isola os objetos uns dos outros, bem como do ambiente e do seu observador (separação). A segunda unifica o que é diverso ou múltiplo, quer àquilo que é elementar quer àquilo que é quantificável (redução). O pensamento fragmentador, portanto, separa para conhecer, e com isso isola as disciplinas científicas entre si, bem como torna a ciência separada da vida social. $O$ pensamento reducionista, de sua parte, percebe e compreende a realidade não conforme a totalidade, "mas aos elementos que a constituem; não às qualidades, mas às medidas; não aos seres e aos entes, mas aos enunciados formalizáveis e matematizantes” (MORIN, 2001, p. 27). Estes dois princípios, muitas vezes, se associam com um outro princípio que Morin denomina de racionalização: "[...] uma visão coerente, totalizante do universo, a partir de dados parciais, de uma visão parcial, ou de um princípio único" (MORIN, 2001, p. 157).

O paradigma da simplificação se alimenta, portanto, da separação, da redução e da racionalização. Este último princípio imagina que a ideia, a teoria, ou o conhecimento, a partir de princípios parciais, contém em si a explicação do mundo e busca a partir disto deduzir todas as consequências práticas. Esses três princípios, em conjunto, produzem o que Morin denomina de pensamento simplificador/mutilador, e é responsável, segundo ele, pelo empobrecimento de nossa inteligência, manifestando no âmbito da política seu maior prejuízo.

Na área jurídica, o determinismo e o paradigma da simplificação (redução, separação, racionalização) se manifestam sempre que se separam as diferentes dimensões que constituem o humano (espécie-indivíduo-sociedade). Muitas vezes se compreende que o problema da violência e da criminalidade seja decorrente unicamente da natureza (biológica) do humano (naturalismo). Em outras vezes se imagina que o problema é da personalidade do indivíduo psíquico (psicologismo), ou mesmo que o problema é unicamente social (sociologismo). Difícil encontrar um pensamento que articula de forma complexa (concorrente, complementar e antagônica) as raízes (biológicas, psíquicas e sociais) da violência e da criminalidade.

Desse modo, um paradigma consiste em uma seleção de conceitos-chave que permitem pensar e interpretar o real. Neste sentido, torna-se importante pensar e conceber na educação e no âmbito do pensamento jurídico uma racionalidade aberta, capaz de autocrítica, a qual

[...] dialoga com o real que lhe resiste. Opera o ir e vir incessante entre a instância lógica e a instância empírica; é o fruto do debate argumentado das idéias, e não a propriedade de um sistema de idéias. O racionalismo que ignora os seres, a subjetividade, a afetividade e a vida é irracional. A racionalidade deve reconhecer a parte de afeto, de amor e de arrependimento (MORIN, 2000, p. 23). 
Morin pensa a ideia de paradigma vinculado com uma perspectiva de racionalidade que, além de ser crítica, precisa ser autocrítica. Isto significa uma potencial abertura para a policromia do real, o que Morin (2003b) também denominou de histeria do real ${ }^{5}$. Não se trata de imaginar algo independente e fora da racionalidade humana, mas de repensá-la, tendo em vista tanto a dimensão lógica e imaginária constitutiva de toda forma de pensamento, quanto à dimensão empírica que o desafia. Este imaginário que sustenta um pensar complexo desafia-nos a repensar os paradigmas herdados da modernidade, criando novas formas de pensar a subjetividade que conhece e o objeto a ser conhecido. Isto significa um novo entendimento sobre o uno e o múltiplo, entre a certeza e a incerteza, entre o todo e as partes, entre a determinação e a indeterminação.

A complexidade, à primeira vista, é um tecido junto de elementos heterogêneos inseparavelmente associados, está ligada a uma mistura de ordem e de desordem, um coquetel de indeterminação na determinação e que pode revelar toda a riqueza do caos (MORIN, 2003a; MORIN, 2003b). Em síntese, afirma o autor, "para mim, a ideia fundamental da complexidade não é que a essência do mundo é complexa e não simples. É que essa essência é inconcebível. A complexidade é a dialógica ordem/desordem/organização" (MORIN, 2003a, p. 151) e em meio à complexidade, ordem e desordem se dissolvem e suas diferenças se dissipam.

De acordo com Morin (2001), o princípio simplificador promove a disjunção entre objeto e meio. Isolando o objeto do meio, a ciência experimental cria um ambiente artificial para a sua observação, submetendo suas variáveis a diferentes condicionantes, o que permite testar suas reações para então conhecê-lo. A questão é que a pretensão de isolamento não conduz à fecundidade do conhecimento acerca do objeto, pois tal propósito depende de suas interações com o meio. Enfim, pelo princípio da simplificação há um corte de separação absoluta entre objeto e sujeito. "O pensamento simplificador promove a disjunção entre o objeto concebido e o sujeito que o percebe e o concebe" (MARTINAZZO, 2004 , p. 42), com isso visa a eliminar toda a problemática do sujeito no conhecimento científico. $O$ sujeito é identificado metafisicamente.

No campo do Direito ocorre um processo semelhante. A legitimidade estatal de decidir os conflitos nascida no seio das teorias contratualistas outorgou a um terceiro o direito de fazer a guerra em nome da paz. Nesse cenário, os conflitantes, unidos pelo conflito, são transformados em litigantes e esperam que um terceiro Ihes diga quem tem mais direito, mais razão, enfim, quem será o vencedor, minimizando a realidade complexa dos conflitos (RESTA, 2004).

A complexidade, por sua vez, admite que em todo o esforço de objetivação está presente a subjetividade, uma vez que a compreensão do objeto é um processo mediado intersubjetivamente. Pela via da complexidade o conhecimento só pode ocorrer na intersubjetividade. Este pressuposto é fundamentável para repensar e reformar a racionalidade jurídica. Trata-se de uma reforma não apenas programática, mas paradigmática. Ela se dá em torno do conhecimento, da forma como nos

\footnotetext{
${ }^{5} \mathrm{Em}$ Morin (2003b), a histeria encontra-se na encruzilhada antropológica do psicoafetivo e do somático, do imaginário e do real, do sentimento e da magia, do jogo e do sério, do simulado e do vivido. É o eu, vivido em sua unidade e em suas dualidades.
} 
relacionamos com os eventos e acontecimentos do mundo. Tanto a ciência do Direito quanto a educação foi concebida no âmbito da teorização moderna a partir de uma perspectiva positivista e simplificadora. Torna-se imperante repensar estes pressupostos, a fim de conceber nova racionalidade, ou seja, nova forma de relacionar os ideais universais e normativos com os cenários contextuais, subjetivos e contingentes.

A partir desse ponto, é possível, também, pensar as implicações do sujeito pensante como produto e produtor de seu pensamento, bem como avaliar em que medida clausuras impostas por uma racionalidade depurada das complexidades humanas - biológicas, espirituais, místicas, afetivas podem resultar na ilusão de conflitos lineares que possam ser funcionalizados pelo Poder Judiciário.

\section{CONFLITO E COMPLEXIDADE}

Embora possam ser muitas as definições sociológicas para os conflitos ${ }^{6}$, há um certo consenso no fato de que o conflito é uma forma de interação entre indivíduos, grupos, organizações e coletividades que resultam em choques, contraposições de ideias, palavras, valores e até mesmo armas, motivado, entre outros fatores, pelo acesso e pela distribuição de recursos escassos, como o poder, a riqueza, o prestígio.

Tais considerações conduzem à conclusão de que existem diversos níveis em que podem ser situados os conflitos - político, econômico, étnico, nacional, internacional - e que envolvem indivíduos, grupos, organizações. Todavia, para além dessas, que são conclusões de consenso, diferentes correntes político-sociológicas buscam atribuir sentido aos conflitos.

Em breve síntese, Rigalia (1998) pontua duas correntes antagônicas. Uma primeira, dos que veem, nos grupos sociais e organizacionais, a harmonia e o equilíbrio - Comte, Spencer, Pareto, Durkheim, Parson - e, por conseguinte, tomam o conflito como uma patologia social, um mal que deve ser reprimido e eliminado, e os segundos, - Marx, Stuart Mill, Simmel, Dahrendorf - que consideram que os grupos e os sistemas sociais são profundamente marcados por conflitos porque, em uma sociedade, o equilíbrio e a harmonia não são normais. Portanto, visualizam nos conflitos, potenciais criativos, sementes de mudanças, progressos e melhoramentos. Identificam conflitos com vitalidade.

Como modo de interação, o conflito destina-se a resolver dualismos divergentes, logrando unidade mesmo que, de modo mais extremo, signifique a aniquilação do outro, seguindo a máxima de que "se você quer paz prepare-se para a guerra". No dualismo, o conflito interliga aspectos antagônicos revelando-se em toda a sua complexidade.

Seguindo na esteira teórica de Simmel (2013), os indivíduos não atingem a unidade de pensamento mediante uma harmonização exaustiva, fundada em acordos baseados em normas de

\footnotetext{
${ }^{6} \mathrm{~A}$ proposta de investigação aqui desenvolvida visa analisar o conflito sob seu viés sociológico, embora não se olvide, até mesmo porque a complexidade alerta, que o conflito possui uma vasta fatia psicológica que ingressa como elemento de formação simbólica nas exteriorizações verbais e corporais dos sujeitos em suas interações sociais, políticas e jurídicas.
} 
lógicas objetivas, religiosas ou éticas. Segundo ele, a unidade social é o produto de convergências e divergências entre os membros de um grupo. Um grupo absolutamente centrípeto e harmonioso, dotado de uma pureza unificadora, é empiricamente irreal. A estrutura orgânica de um conjunto humano de sociação ${ }^{7}$ é produto de seus antagonismos, e é na pluralidade de ideias em contraposição que nasce toda a vivacidade e coesão orgânica de uma reunião de pessoas. Até mesmo o universo, escreve o autor, para ter forma

[...] necesita um combinado de armonía y disonancia, de asociación e lucha, de simpatia y antipatia para definir su forma. $Y$ estos binomios em modo alguno son meros pasivos sociológicos, factores negativos, que la sociedad habría de superar para poder existir; la sociedad, es efectivamente, el resultado de la interacción entre las dos categorías. Es decir, tanto las tendências unitárias como las disgregadoras son constitutivas de la sociedad y, em este sentido, son positivas. (SIMMEL, 2013, p. 19).

Simmel (2013) trabalha com um dos princípios da complexidade, ou seja, que a unidade engloba os contrários. Insurge-se em relação às concepções tradicionais de interações humanas pela lógica da disjunção entre os contrários, entre o positivo e o negativo, o verdadeiro e o falso. Afirma que o negativo não deve ser eliminado para que o positivo possa construir a verdadeira vida. A felicidade $e$ a dor, a virtude e o vício, o fracasso e o êxito compõem a totalidade da vida, e o sentido global da existência nasce da interação dessas partes.

Tendo em conta que a unidade e a harmonia não são produto de uma simples e linear aplicabilidade de normas lógicas e objetivas, mas se dão nos encontros e desencontros, nas antíteses e convergências, a compreensão da dimensão criativa do conflito conduz ao âmago do sujeito e deflagra novas leituras para a regulação das divergências humanas. De acordo com Warat (2001), para abrir as portas do céu, é preciso primeiro passar pelo inferno e antes de evaporar é necessário ferver, assim, as transformações alquímicas que podem conduzir à ordem devem ser jogadas sobre o tabuleiro da autenticidade dos contrários. No ódio, na raiva, na desordem, desnuda-se o caos e as possibilidades de novos arranjos na administração dos conflitos.

No entanto, qual seria a chave para a entrega plena ao caos, como pré-condição de reorganização de um grupo, de uma família, da sociedade, ou mesmo da humanidade? A chave pode estar no viver, no sentir o sentimento, no avançar no sentido das ambiguidades humanas, inacessíveis pela manipulação de conceitos empíricos, pelo pensamento e pela linguagem da racionalidade lógica. Dialogando com a complexidade, Warat (2001, p. 35) escreve:

Semioticamente falando existem duas linguagens na linguagem, duas intenções de expressão, uma dupla função: uma é prosa fática, a linguagem dos conceitos, dos pensamentos, do ego, da mente e das verdades determinadas pela razão conceitual; a outra é a poesia, a linguagem que nos comunica com as reservas selvagens que, de repente, irrompe para revelar a fragrância das

\footnotetext{
${ }^{7}$ Conceito cunhado por Simmel (2013) para designar o conjunto de interações sociais e as relações de interdependência, não necessariamente convergentes, entre indivíduos que formam uma sociedade, independente de um território ou uma localidade.
} 
coisas do inconsciente amoroso, o que unicamente pode chegar pela experiência melódica dos sentimentos.

O pensamento conceitual pode ser fragmentário e corre o risco de não dialogar com o real. O sentimento, por sua vez, implica o convocar do corpo, da contingência, da sensibilidade. Os processos que vêm do pensamento, especialmente do pensamento fragmentário, em linhas gerais, conduzem a acordos que não se podem cumprir, pois a totalidade do ser não está implicada. Os acordos como convergências conflitivas, na perspectiva da complexidade, não são apenas acordos de palavras, ou mesmo racionais, são acordos do coração, ou mesmo sensíveis, da humanidade da humanidade; processos animados desde os sentimentos nos quais as escolhas implicadas no ser e no viver renunciam à hipocrisia e dançam na dualidade da moral.

Morin faz referência a uma bastardice da moral, em uma espécie de moral sem um fundamento teórico único, racional, dogmático, de certezas e imperativos generalizantes. O autor nos evidencia que existe no mundo humano uma moral da anomia e não apenas uma moral do compromisso, a qual está conectada com uma realidade antropológica fundamental. Esta unidualidade da moral é capaz de refletir e revelar "esse misto de coerência e incoerência, de ordem e de desordem, de reversibilidade e de irreversibilidade, de racional e de irracional, que constitui o caos do mundo" (MORIN, 2003b, p. 190). Morin quer nos desafiar a pensar e entender a condição humana em sua complexidade e isto implica assumir certa ambivalência constitutiva do agir moral humano. Este desafio coloca-se como fundamental para todos os que lidam com a educação, o conhecimento e a formação humana, bem como com todos aqueles implicados de forma especial com a formação de pessoas relacionadas ao pensamento e ao exercício do Direito.

A Teoria da Complexidade parece indicar como via paradigmática para pensar o Direito e a condição humana, não uma aposta na razão fria e calculista do pensamento conceitual e universal $a$ priori concebido, mas a necessidade de se gestar uma nova racionalidade, que lute contra toda forma de fragmentação do conhecimento humano que torna o real unidimensional. Esta via parece implicar também o envolvimento da sensibilidade, da imaginação, do diálogo, entre o universal e o particular, entre a parte e o todo, tendo em vista a complexidade do real, de seus contextos e contingências. Com isso, esta teoria cria modos de refundar o pensamento moderno acerca da forma como podem ser enfrentados os conflitos humanos. O humano, nesta teoria, é complexo e alimenta-se de conflitos, de antagonismos, como também de consensos. O pensamento complexo não reduz o humano e nem a existência ao que pode ser expresso matematicamente, mas entende que o todo precisa ser compreendido no interior de cada uma das partes e vice-e-versa, bem como na relação complexa entre elas. A desordem, o aleatório presente no conflito, em perspectiva de complexidade, cumpre um papel produtor no mundo, porém, largamente esquecido na modernidade. 


\section{CONSIDERAÇÕES FINAIS}

O Direito, como produto da racionalidade jurídica moderna, reivindica a superação da violência e gera respostas coercitivas, mediante o monopólio da violência legítima. Uma racionalização ordenada e expurgada da desordem é capaz de eliminar conflitos, mediante decisões judiciais, oriundas de um terceiro, ao qual o Estado conferiu a legitimidade de traduzir as regras predispostas e fixar os limites de atuação dos conflitantes. Assim, o cidadão da modernidade, na condição de coadjuvante, unido pelo conflito, aguarda passivo para que digam quem tem direito ou mais direito após a institucionalização de um litígio.

Desse modo, o modelo de justiça ofertado pelo sistema jurisdicional acirra a dialética entre a "realidade institucionalizada" e a "perspectiva do homem", pois transcreve o conflito em uma linguagem jurídica e o encerra entre os muros do procedimento judiciário. Por intermédio de metadiscursos jurídicos, o juiz atrai para o seu universo o conflito e transforma, judicializa tudo aquilo que vem ao seu domínio, sem, contudo, conhecer o conflito em sua substância.

O Poder Judiciário institucionaliza conflitos sociais, porém, as suas decisões não eliminam relações sociais; decidirá o litígio, mas não impedirá a ressignificação do conflito, pois ele é capaz de funcionalizar o conflito social; no entanto, não tem a capacidade de fazer o mesmo com a vida das pessoas. Ainda, a imparcialidade judicial, imperativo legitimador da justiça, impõe o afastamento entre o juiz e o conflito. A decisão refere-se a "litígios" que são alheios ao juiz, sob os quais não deve sentir e sequer assumir responsabilidades, uma vez que a responsabilidade pelo conteúdo da escolha não é do magistrado, pois projetada para a muralha normativa.

A Teoria da Complexidade se constitui em um aporte teórico com potencial para revelar a insuficiência do pensamento jurídico moderno em relação à complexidade dos conflitos atuais, multifacetados e próprios de uma realidade social cada vez mais excludente. Convida a refletir acerca do conflito a partir dos princípios da inteligibilidade complexa, os quais se propõem a unir noções antagônicas como ordem/desordem, organização/desorganização, determinação/indeterminação e que permitem integrar, na noção do conflito a razão, o misticismo, a sabedoria, o amor e a loucura. O olhar, a partir da teoria da complexidade, possibilita penetrar no âmago da realidade e dialogar com tudo aquilo que se apresenta como algo ambivalente e conflituoso.

Além disso, o viés da complexidade nos permite entrever o paradigma constitutivo da racionalidade fundante do mundo moderno, conferindo um destaque particular para a educação. Neste sentido, ele permite um diagnóstico de fundo acerca da noção de ciência/racionalidade que se tornou referencial na estruturação da formação do bacharel em Direito, bem como na educação em geral.

A tematização e crítica do paradigma da simplificação e aos seus princípios lógicos, da separação, da redução, da ordem e da certeza, possibilita a Morin compreender o nó górdio do 
pensamento linear moderno que orientou e organizou o sistema de educação. No âmbito da formação em Direito, este diagnóstico sinaliza para a necessidade de outra forma de compreender a realidade e o próprio conhecimento, a partir de um paradigma complexo, o que significa um maior valor e diálogo entre as culturas das humanidades (reflexivas e interrogantes) e as culturas tecnocientíficas (normativas e instrumentalizantes).

Assumir esta perspectiva teórica no âmbito do Direito e da educação é adentrar uma nova perspectiva de formação e de uso da razão. Mais que isso, é ajudar a repensar a cultura e o modelo educacional, epistemológico e jurídico herdados da modernidade. Repensar, de fato, não significa abandonar o espírito das luzes, das conquistas da modernidade, mas, simplesmente colocar sob nova chave de leitura também os limites e as limitações acerca do paradigma simplificador que fundou as bases da ciência e da racionalidade que atravessa o universo cultural do Direito e da educação.

Enfim, cumpre a nós, na contemporaneidade, conceber um pensamento complexo, para uma humanidade complexa, para o humano que se alimenta dos conflitos e dos antagonismos, um modo de pensar que não reduza a existência a expressões compreensíveis pelas lentes monoculares empíricoracionalistas e que possa substituir o pensamento disjuntivo e redutor pelo que une, pela compreensão do todo e das partes, da potência da subjetividade, dos afetos, do inconsciente, da parcela irracional da realidade, do medo, do arrependimento, ingredientes necessariamente presentes nos conflitos e que não podem ser ignorados pela racionalidade jurídica contemporânea.

\section{REFERÊNCIAS}

1. KELSEN, Hans. Teoria Pura do Direito. São Paulo: Martins Fontes, 2006.

2. MARTINAZZO, Celso J. A utopia de Edgar Morin: da complexidade à concidadania planetária. 2 . ed. ljuí: Editora Unijuí, 2004.

3. MORIN, Edgar. Os sete saberes necessários à educação do futuro. São Paulo: Cortez; Brasília, DF: Unesco, 2000.

4. __ Ciência com consciência. Rio de Janeiro: Bertrand Brasil, 2001.

5. . Introdução ao pensamento complexo. Lisboa: Instituto Piaget, 2003a.

6. X da questão: o sujeito à flor da pele. Porto Alegre: Artmed, 2003b.

7. RESTA, Elígio. O Direito Fraterno. Santa Cruz do Sul: Edunisc, 2004. 
8. RIGALIA. Ida. Conflito. In: BOBBIO, Norberto; MATTEUCCI, Nicola; PASQUINO, Gianfranco (orgs.). Dicionário de Política. Brasília: Universidade de Brasília, 1998. p. 225-230.

9. ROCHA, Leonel Severo. O direito na forma de sociedade globalizada. In: Anuário do Programa de Pós-Graduação em Direito da Unisinos. São Leopoldo: Unisinos, 2001.

10. SIMMEL, Georg. El Conflito: sociologia del antagonismo. Madrid: Ediciones Sequitur, 2013.

\section{Celso José Martinazzo}

Professor titular na Unijuí/RS. Licenciado em Filosofia e Pedagogia e especialização em Orientação Educacional. Mestrado em Educação (UFSM) e doutorado em Educação (UFRGS). Pós-doutorado, com bolsa da Capes, na Uminho/Portugal.

\section{Fernanda Serrer Scherer}

Possui graduação em Direito pela Universidade Regional do Noroeste do Estado do Rio Grande do Sul e pós-graduação em Direito Processual Civil e mestrado em Desenvolvimento, Gestão e Cidadania pela Universidade Regional do Noroeste do Estado do Rio Grande do Sul (2004). Atualmente é professora na graduação do Curso de Direito da Universidade Regional do Noroeste do Estado do Rio Grande do Sul-UNIJUI.

\section{Sidinei Pithan da Silva}

Possui graduação em Educação Física pela Universidade Federal de Santa Maria, graduação em Farmácia pela Universidade Federal de Santa Maria, graduação em História pela Universidade Regional do Noroeste do Estado do Rio Grande do Sul, mestrado em Educação nas Ciências pela Universidade Regional do Noroeste do Estado do Rio Grande do Sul e doutorado em Educação pela Universidade Federal do Paraná. Atualmente é professor do Curso de Educação Física (EDF) da UNIJUÍ-RS e do Mestrado e do Doutorado em Educação nas Ciências da UNIJUÍ-RS.

\section{Como citar este docuemnto:}

MARTINAZZO, Celso José; SCHERER, Fernanda Serrer; SILVA, Sidinei Pithan da. Teoria da complexidade e racionalidade jurídica contemporânea: (re)pensando a complexidade dos conflitos. Reflexão e Ação, Santa Cruz do Sul, v. 26, n. 3, nov. 2018. ISSN 1982-9949. Disponível em: <https://online.unisc.br/seer/index.php/reflex/article/view/12403>. Acesso em: 19 nov. 2018. doi:https://doi.org/10.17058/rea.v26i3.12403. 
Reflexão e Ação [ISSN 1982-9949]. Santa Cruz do Sul, v. 26, n. 3, p. 91-105, set./dez. 2018.

https://online.unisc.br/seer/index.php/reflex/index 